\title{
Impact of marijuana legalization on prevalence of maternal marijuana use and perinatal outcomes
}

\author{
Mayi GNOFAM ${ }^{1,2}$, Ms. Amanda A. ALLSHOUSE ${ }^{3}$, Elaine H. STICKRATH ${ }^{4,5}$, Torri D. METZ 3 \\ 1.Department of Obstetrics and Gynecology, University of Colorado Denver, Aurora, CO \\ 2.Department of Obstetrics and Gynecology, Maison Blanche's Hospital, University of Reims \\ Champagne-Ardenne. \\ 3.Department of Obstetrics and Gynecology, University of Utah Health, Salt Lake City, UT \\ 4.Department of Obstetrics and Gynecology, Denver Health and Hospital Authority, Denver, CO \\ 5. University of Colorado School of Medicine, Aurora, CO
}

\section{Abstract}

Objective: We aimed to assess whether marijuana legalization was associated with a difference in prevalence of prenatal use or an increase in incidence of adverse perinatal outcomes.

\begin{abstract}
Study design: Retrospective cohort of September and October deliveries in the years 2012 through 2015 at a tertiary center in Colorado. Primary outcome was marijuana use, defined by self-report, or bio-detection. Secondary outcomes included: growth restriction, spontaneous preterm birth, stillbirth, preeclampsia, and neonatal or maternal death. Marijuana use prevalence was compared by year, and secondary outcomes between two periods - before and after the opening of the first recreational dispensary.
\end{abstract}

Results: A total of 2392 pregnant women were included (1165 before legalization and 1227 after). More women used marijuana over the period of legalization (trend $\mathrm{p}=0.01$ ). Odds of marijuana use were higher after legalization versus before (aOR 1.8, 95\% CI 1.2-2.6).

Incidence of growth restriction was higher after legalization ( $2.9 \%$ versus $5.1 \%, \mathrm{p}=0.0084)$. This difference persisted after adjustment for ethnicity and other drugs in multivariable modeling (aOR $1.9,95 \%$ CI 1.2-3.0).

Conclusion: The prevalence of prenatal marijuana use increased over the time of legalization. Further investigation into the population impact of legalization on obstetrical outcomes is warranted given the observed increase in growth restriction.

\section{Keywords}

alcohol; cannabis; fetal growth restriction; legalization; marijuana; opioids; pregnancy; prevalence; tobacco

Corresponding author: Torri Metz, MD, MS, University of Utah Health, 30 North 1900 East, 2B200, Salt Lake City, UT, 84132, Work phone: (801) 581-8425, Work fax: (801) 585-2594, torri.metz@ hsc.utah.edu.

The authors report no conflicts of interest.

Presented as a poster at the Society for Maternal-Fetal Medicine Annual Meeting, Las Vegas, NV, February 11-16, 2019. 


\section{Introduction}

Marijuana is the most widely used "illicit" drug among pregnant women with estimates ranging from 3-30\% (1-4). Many studies have focused on the impact of marijuana use on obstetrical outcomes (5). Use has been associated with lower neonatal birthweights (6-14), altered fetal neurological development (15-20), and stillbirth (21). Despite a potential risk of harm, the prevalence of marijuana use and perceived safety of use has trended up over a period of expanding legalization in the United States $(22,23)$. It remains unclear, however, how legalization of recreational marijuana impacts the prevalence of use among pregnant women.

Most studies evaluating the impact of marijuana legalization on prevalence of use focus on youth, and demonstrate no association between marijuana legalization and increased consumption (24-28). However, these results are mixed. One study focusing on Washington State University undergraduate students highlighted a significant increase in marijuana use after legalization, with the greatest change observed among females, Black and Hispanic students (29). Another study demonstrated a ten-year increase in adolescent marijuanaassociated emergency department visits in Colorado, most notably in the years following commercialization of medical and recreational marijuana (30). There was similarly an increase in hospitalizations with marijuana-related codes by $70 \%$ between 2013 and 2015 (the years surrounding recreational legalization).

Data regarding the impact of legalization of recreational marijuana on the prevalence of marijuana use among pregnant women are lacking. We therefore aimed to assess whether legalization of marijuana in Colorado was associated with a difference in prevalence of marijuana use during pregnancy or a change in the incidence of adverse pregnancy outcomes. We hypothesized that marijuana use by pregnant women would increase following recreational legalization.

\section{Material and Methods}

Over the past two decades, Colorado has legalized marijuana for both medicinal and recreational use. While medical marijuana was legalized in 2000, sales did not begin until 2009. Recreational marijuana was then legalized in November 2012, with the first sales beginning January 1, 2014 (31). To assess whether recreational legalization of marijuana in Colorado was associated with a difference in prevalence of marijuana use during pregnancy, or incidence of adverse perinatal outcomes, we designed a study to compare women who delivered before and after January 1, 2014.

We performed a retrospective cohort study including all deliveries at a university-affiliated tertiary center in Colorado in September and October of the years: 2012, 2013, 2014 and 2015. All women who delivered during the study time period were included. If women had more than one birth during the study time period, only the first birth was included.

September and October were selected as the months for analysis as they were remote from policy changes, and not near the beginning or end of the academic year. 
Women were identified by using a previously created perinatal database (extracted from an Epic electronic medical record system) that identifies all deliveries occurring at the institution for each monthly interval. Given the increased incidence of adverse pregnancy outcomes among women with multiple gestations, women with multiple gestations were included in the overall marijuana prevalence estimate, but excluded from estimates of perinatal outcomes. This study was approved by the Colorado Multiple Institutional Review Board.

Detailed demographic and delivery data were abstracted from the electronic medical record of each participant by trained perinatal research assistants. Abstracted medical record data were entered into a study-specific instance of Research Electronic Data Capture (REDCap) hosted at the University of Colorado Denver Anschutz Medical Campus, a secure, webbased application designed to support data capture for research studies (32).

Demographic data abstracted included: ethnicity (Hispanic, not Hispanic), race (Black or African American, Native American or Alaskan, Asian, Native Hawaiian or Other Pacific Islander, White, More than one race, other), maternal age at delivery in years, marital status (married or living with partner, single or significant other, divorced or legally separated), employment status (employed, unemployed), education status (less than high school, high school, some college, completed college, higher degree), and gestational age at delivery in weeks.

The primary outcome was marijuana use. Marijuana use was defined by self-report as documented in the medical record, bio-detection with urine toxicology at either the first prenatal visit or at admission for delivery as ordered by a clinician, or meconium testing positive for cannabis metabolites as ordered by a clinician during the neonatal delivery admission. There was no specific hospital protocol for who met criteria for drug testing over the study period. Per hospital protocol, written maternal consent was required for maternal urine toxicology testing. Meconium testing and neonatal urine testing were sent at the discretion of pediatrics without maternal consent.

Secondary outcomes were fetal growth restriction (FGR), as detected antenatally by ultrasound with an estimated fetal weight $<10 \%$ ile, spontaneous preterm birth at $<37$ weeks gestation, stillbirth, preeclampsia (with and without severe features), fetal congenital anomalies, gestational diabetes, mode of delivery (spontaneous vaginal, forceps, vacuum or cesarean), neonatal death, maternal death, small for gestational age (SGA), NICU admission, and $>2$ days in NICU. Fetal growth restriction was ascertained based on the reported estimated fetal weight by ultrasound. Ultrasounds were ordered at the discretion of the providers for lagging fundal height or obstetric indications. Marijuana use was not an indication for obtaining a growth ultrasound over the study time period.

Self-report of other drugs, alcohol and tobacco were recorded. All results from urine toxicology testing and meconium testing were abstracted from the charts of both mothers and neonates when available. 


\section{Statistical methods}

Deliveries were grouped by year into four categories (2012-15) for test of trend, and then separately into two categories designating time before (2012-2013) and after (2014-2015) legalization for further comparisons and modeling. Demographics and secondary outcomes are reported before and after legalization, and compared using a chi-square test for categorical measures and a t-test for continuous measures. Employment status and education level were missing for the majority of participants, and are therefore not reported.

Prevalence of marijuana use is reported before and after legalization and by year, with differences in prevalence across years tested using a chi-square test for trend. The overall chi-square for the comparison across 4 years is also reported. All demographic variables that were different between groups $(\mathrm{p}<0.05)$ were considered for inclusion in multivariable modeling for our primary and secondary outcomes. Other drug use was considered a clinically important covariate for perinatal outcomes and was, therefore, included in all models for our secondary outcomes. The final multivariable logistic regression models were estimated adjusting for ethnicity and other drug use as appropriate.

To evaluate the accuracy of manual chart abstraction, $5 \%$ of the eligible records were randomly selected. These charts were abstracted again for the primary and secondary outcomes. Repeat data abstraction was completed by the Obstetric Research Team at the University of Colorado, which is comprised of trained perinatal research assistants and nurses. Repeat abstraction was performed without knowledge of the original data entry. Concordance between the two abstractions was evaluated, and they were found to be concordant $>95 \%$ (range $95.6-99.2 \%$ ) of the time for all outcomes. If there was a discrepancy between the abstractions, this was corrected through adjudication by one of the investigators. Differences were considered significant at $\mathrm{p}<0.05$. All analyses were performed in SAS. Figures were created using GraphPad PRISM.

\section{Results}

Among 2428 deliveries occurring in September or October across 4 years, 36 deliveries were excluded as they were identified as the second delivery from a woman already included in the study. Among the remaining 2392 women who were included: 566 women delivered in 2012, 599 in 2013, 630 in 2014 and 597 in 2015. Women who delivered before ( $\mathrm{n}=1165)$ and after ( $\mathrm{n}=1227$ ) legalization differed by ethnicity, and by self-reported race as "other". Other demographic characteristics did not significantly differ between the two groups (Table 1).

\section{Primary outcome}

More pregnant women self-reported marijuana use over the period of legalization ( $2.8 \%$ in $2012,3.7 \%$ in $2013,7.3 \%$ in $2014,4.9 \%$ in 2015 , trend $\mathrm{p}=0.01$ ). Similarly, significantly more pregnant women reported using marijuana before compared to after legalization (3.3 vs $6.0 \%, p=0.001$ ). Among the subset of $n=100$ women ( $n=41$ before, $n=59$ after) for whom a urine toxicology test was available at the time of delivery, detected use was significantly different before versus after legalization ( $7 \%$ versus $29 \% \mathrm{p}=0.01)$. Among the subset of 
$\mathrm{n}=801$ neonates with meconium testing available during the delivery admission, detected use was not statistically different before versus after legalization ( $1.5 \%$ versus $3.1 \%, \mathrm{p}=0.13$ ). Combining all sources of marijuana use (self-report or biologically detected), use trended significantly higher over the period of legalization (3.7\% in 2012, $4.7 \%$ in 2013, $8.6 \%$ in $2014,5.9 \%$ in 2015, trend $\mathrm{p}=0.02$, Figure 1). After adjustment for ethnicity, odds of marijuana use remained significantly higher after legalization than before (aOR 1.8, 95\% CI $1.2-2.5)$.

Positivity of both urine sample at delivery and meconium testing significantly differed over time but without a significant trend by year. Positivity of urine sample at the first prenatal visit did not significantly differ over time. The use of other substances (tobacco, alcohol, illegal drugs, opioids) did not differ significantly over time for self-reported or biologically detected use (Table 2).

\section{Secondary outcomes}

Perinatal outcomes were compared before versus after legalization for $n=2321$ singleton deliveries (multiple gestations excluded for this portion of the analysis). The incidence of antenatally diagnosed fetal growth restriction was significantly higher after legalization ( $2.9 \%$ versus $5.1 \%, \mathrm{p}=0.006$ ) (Table 3 ). This difference persisted after adjustment for ethnicity and other drugs in multivariable modeling (aOR 1.9, 95\% CI 1.3-3.1). For all other neonatal, obstetrical outcomes, and delivery characteristics, observed differences were not significantly different before and after legalization (Table 3).

\section{Discussion}

We found a significantly higher prevalence of prenatal marijuana use over the time period of recreational legalization in Colorado. More women self-reported marijuana use, and had a positive urine or meconium test at delivery. No difference was found over time for other substances including tobacco, alcohol, illegal drugs or opioids. Among singleton deliveries, fetal growth restriction had a higher incidence after legalization while other evaluated perinatal outcomes did not significantly differ.

Overall, our findings are consistent with those of Miller et al (29) who noted a significant increase in marijuana self-reported use but not in tobacco, alcohol or other drugs in a youth population. Recent data from the Colorado Department of Public Health and Environment similarly highlight a significantly higher prevalence of marijuana use during pregnancy among younger women (less than 24 years old) (33) following legalization, especially in the setting of an unintended pregnancy. Our results are also consistent with those of the 20072012 National Surveys on Drug Use and Health as we found a similar prevalence of use among pregnant women in 2012 (4).

The prevalence of use by urine or meconium testing increased from 7\% prior to legalization to $26 \%$ after legalization. While only a small proportion of the women in our study had biological sampling results available, the results are similar to a previous study using a cross-sectional universal cord homogenate sampling approach at two Colorado hospitals after recreational legalization (34). The cross-sectional study reported a prevalence of use of 
$22 \%$ by cord sampling. Those findings and ours indicate that many women use marijuana during pregnancy in a state with legalization demonstrating the importance of screening for and discussing use in pregnancy. Of note, in this cross-sectional study the proportion of women who self-reported use was much lower (6\% on an anonymous survey), which is consistent with the results of this analysis, and reflects a major limitation of studies relying on self-reported use.

To our knowledge, this is one of the first studies to evaluate whether marijuana legalization is associated with differences in use among pregnant women. Data were abstracted from medical records without reliance on administrative coding for substance use, which likely underestimates use. We observed increased self-reported, and biologically detected, prevalence of marijuana use among pregnant women after legalization. The increase was most notable in the year immediately following recreational legalization, which may reflect liberalized reporting of use prior to an understanding of the ongoing ramifications of mandatory reporting of maternal use of schedule I substances regardless of state-level policy.

While we found an increase in diagnosis of fetal growth restriction from before to after legalization, there was not a similar observed increase in the incidence of small for gestational age at birth. This raises the question of whether there was bias in the selection of women for ultrasound to evaluate for fetal growth restriction. This association warrants further investigation with prospective assessment of fetal growth in a cohort of women with and without marijuana use over the course of pregnancy. Marijuana use was associated with decreased fetal growth by ultrasound among a cohort of women participating in the Generation R study (6).

We did not find differences in neonatal outcomes from before to after legalization. Data regarding the association between marijuana use and perinatal outcomes are limited by lack of adjustment for important confounding factors, as well as, the use of self-reported marijuana use as the exclusive means of ascertainment of use (1)(5). However, there are data supporting an association between NICU admission and marijuana exposure (1).

Importantly, in our analysis, we compared rates of perinatal outcomes before and after legalization, but did not evaluate the impact of marijuana use directly, which may account for the observed differences between our findings and those previously published.

Our study has several limitations. The results are largely based on self-reported marijuana use and pregnant women may have been more likely to disclose marijuana use in the era of legalization. Self-report is known to have a very high specificity for use at the expense of a low sensitivity, compared to biological sampling (35) (36). Therefore, our results may underestimate use. However, we also considered prevalence of use of other addictive substances (tobacco, alcohol and other illegal drugs) over the same time period using the same self-reported methodology, and found no similar increase. In addition, urine toxicology testing was not completed universally, which may bias the results to a higher estimated prevalence of use by sampling women at higher risk. Similarly, screening for fetal growth restriction with ultrasound was only performed when clinically indicated which may result in bias. Finally, the study was completed at a single tertiary care center and the results may not be generalizable to other populations. 


\section{Conclusion}

Our results demonstrate that the prevalence of prenatal marijuana use increased over the time period of recreational marijuana legalization in Colorado. For other states preparing for a change in legal status of marijuana, we recommend implementation of systematic biologic testing leading up to and through the time of legalization to thoroughly evaluate the impact of marijuana policy change. In addition, the finding of increased incidence of fetal growth restriction from before to after legalization is concerning, and needs to be evaluated in other populations.

\section{Acknowledgements}

The authors would like to thank the research assistants with the CTRC Perinatal Research Team and the Obstetrics Research Team at the University of Colorado for their assistance with data abstraction for this project.

Funding Source: This project was completed using resources (REDcap) from the Colorado Clinical \& Translational Sciences Institute (CCTSI) with the Development and Informatics Service Center (DISC) grant support (NIH/NCRR Colorado CTSI Grant Number UL1 RR025780). During the completion of this study, Dr. Metz was supported by the National Institute on Child Health and Human Development under award number 5K12HD001271-18. The content is solely the responsibility of the authors and does not necessarily represent the official views of the National Institutes of Health.

\section{References}

1. Metz TD, Borgelt LM. Marijuana Use in Pregnancy and While Breastfeeding. Obstet Gynecol. 2018 11;132(5):1198-210. [PubMed: 30234728]

2. Metz TD. What Is New in Cannabis Use in Pregnancy?: Best Articles From the Past Year. Obstet Gynecol. 2018 3;131(3):594-5. [PubMed: 29420416]

3. Metz TD, Allshouse AA, Hogue CJ, Goldenberg RL, Dudley DJ, Varner MW, et al. Maternal marijuana use, adverse pregnancy outcomes, and neonatal morbidity. Am J Obstet Gynecol. 2017;217(4):478.e1-478.e8. [PubMed: 28578174]

4. Ko JY, Farr SL, Tong VT, Creanga AA, Callaghan WM. Prevalence and patterns of marijuana use among pregnant and nonpregnant women of reproductive age. Am J Obstet Gynecol. 2015 8;213(2): 201.e1-201.e10. [PubMed: 25772211]

5. Metz TD, Stickrath EH. Marijuana use in pregnancy and lactation: a review of the evidence. Am J Obstet Gynecol. 2015 12;213(6):761-78. [PubMed: 25986032]

6. El Marroun H, Tiemeier H, Steegers EAP, Jaddoe VWV, Hofman A, Verhulst FC, et al. Intrauterine cannabis exposure affects fetal growth trajectories: the Generation R Study. J Am Acad Child Adolesc Psychiatry. 2009 12;48(12):1173-81. [PubMed: 19858757]

7. Gray TR, Eiden RD, Leonard KE, Connors GJ, Shisler S, Huestis MA. Identifying prenatal cannabis exposure and effects of concurrent tobacco exposure on neonatal growth. Clin Chem. 2010 9;56(9): 1442-50. [PubMed: 20628142]

8. Hatch EE, Bracken MB. Effect of marijuana use in pregnancy on fetal growth. Am J Epidemiol. 1986 12;124(6):986-93. [PubMed: 3776981]

9. Hingson R, Alpert JJ, Day N, Dooling E, Kayne H, Morelock S, et al. Effects of maternal drinking and marijuana use on fetal growth and development. Pediatrics. 1982 10;70(4):539-46. [PubMed: 6981792]

10. Hurd YL, Wang X, Anderson V, Beck O, Minkoff H, Dow-Edwards D. Marijuana impairs growth in mid-gestation fetuses. Neurotoxicol Teratol. 2005 4;27(2):221-9. [PubMed: 15734273]

11. Zuckerman B, Frank DA, Hingson R, Amaro H, Levenson SM, Kayne H, et al. Effects of maternal marijuana and cocaine use on fetal growth. N Engl J Med. 19893 23;320(12):762-8. [PubMed: 2784193]

12. Janisse JJ, Bailey BA, Ager J, Sokol RJ. Alcohol, tobacco, cocaine, and marijuana use: relative contributions to preterm delivery and fetal growth restriction. Subst Abuse. 2014;35(1):60-7. 
13. Kline J, Stein Z, Hutzler M. Cigarettes, alcohol and marijuana: varying associations with birthweight. Int J Epidemiol. 1987 3;16(1):44-51. [PubMed: 3570621]

14. Shiono PH, Klebanoff MA, Nugent RP, Cotch MF, Wilkins DG, Rollins DE, et al. The impact of cocaine and marijuana use on low birth weight and preterm birth: a multicenter study. Am J Obstet Gynecol. 1995 1;172(1 Pt 1):19-27. [PubMed: 7847533]

15. de Moraes Barros MC, Guinsburg R, de Araújo Peres C, Mitsuhiro S, Chalem E, Laranjeira RR. Exposure to marijuana during pregnancy alters neurobehavior in the early neonatal period. $\mathrm{J}$ Pediatr. 2006 12;149(6):781-7. [PubMed: 17137892]

16. Fried PA. The Ottawa Prenatal Prospective Study (OPPS): methodological issues and findings--it's easy to throw the baby out with the bath water. Life Sci. 1995;56(23-24):2159-68. [PubMed: 7539879]

17. Goldschmidt L, Richardson GA, Willford J, Day NL. Prenatal marijuana exposure and intelligence test performance at age 6. J Am Acad Child Adolesc Psychiatry. 2008 3;47(3):254-63. [PubMed: 18216735]

18. Goldschmidt L, Day NL, Richardson GA. Effects of prenatal marijuana exposure on child behavior problems at age 10. Neurotoxicol Teratol. 2000 6;22(3):325-36. [PubMed: 10840176]

19. Gray KA, Day NL, Leech S, Richardson GA. Prenatal marijuana exposure: effect on child depressive symptoms at ten years of age. Neurotoxicol Teratol. 2005 6;27(3):439-48. [PubMed: 15869861]

20. Day NL, Goldschmidt L, Thomas CA. Prenatal marijuana exposure contributes to the prediction of marijuana use at age 14. Addict Abingdon Engl. 2006 9;101(9):1313-22.

21. Varner MW, Silver RM, Rowland Hogue CJ, Willinger M, Parker CB, Thorsten VR, et al. Association between stillbirth and illicit drug use and smoking during pregnancy. Obstet Gynecol. 2014 1;123(1):113-25. [PubMed: 24463671]

22. Brown QL, Sarvet AL, Shmulewitz D, Martins SS, Wall MM, Hasin DS. Trends in Marijuana Use Among Pregnant and Nonpregnant Reproductive-Aged Women, 2002-2014. JAMA. 2017 10;317(2):207-9. [PubMed: 27992619]

23. Jarlenski M, Koma JW, Zank J, Bodnar LM, Bogen DL, Chang JC. Trends in perception of risk of regular marijuana use among US pregnant and nonpregnant reproductive-aged women. Am J Obstet Gynecol. 2017;217(6):705-7. [PubMed: 28843740]

24. Ammerman S, Ryan S, Adelman WP, Committee on Substance Abuse, the Committee on Adolescence. The impact of marijuana policies on youth: clinical, research, and legal update. Pediatrics. 2015 3;135(3):e769-785. [PubMed: 25624385]

25. Choo EK, Benz M, Zaller N, Warren O, Rising KL, McConnell KJ. The impact of state medical marijuana legislation on adolescent marijuana use. J Adolesc Health Off Publ Soc Adolesc Med. $20148 ; 55(2): 160-6$.

26. Lynne-Landsman SD, Livingston MD, Wagenaar AC. Effects of state medical marijuana laws on adolescent marijuana use. Am J Public Health. 2013 8;103(8):1500-6. [PubMed: 23763418]

27. Mason WA, Fleming CB, Ringle JL, Hanson K, Gross TJ, Haggerty KP. Prevalence of marijuana and other substance use before and after Washington State's change from legal medical marijuana to legal medical and nonmedical marijuana: Cohort comparisons in a sample of adolescents. Subst Abuse. 2016 6;37(2):330-5.

28. Jones J, Nicole Jones K, Peil J. The impact of the legalization of recreational marijuana on college students. Addict Behav. 2018 2;77:255-9. [PubMed: 29107203]

29. Miller AM, Rosenman R, Cowan BW. Recreational marijuana legalization and college student use: Early evidence. SSM - Popul Health. 2017 12;3:649-57. [PubMed: 29349253]

30. Wang GS, Davies SD, Halmo LS, Sass A, Mistry RD. Impact of Marijuana Legalization in Colorado on Adolescent Emergency and Urgent Care Visits. J Adolesc Health Off Publ Soc Adolesc Med. 20183 30;

31. Monte AA, Zane RD, Heard KJ. The implications of marijuana legalization in Colorado. JAMA. 20151 20;313(3):241-2. [PubMed: 25486283]

32. Harris PA, Taylor R, Thielke R, Payne J, Gonzalez N, Conde JG. Research electronic data capture (REDCap)--a metadata-driven methodology and workflow process for providing translational research informatics support. J Biomed Inform. 2009 4;42(2):377-81. [PubMed: 18929686] 
33. Pregnancy Risk Assessment Monitoring System (PRAMS): Monitoring trends in marijuana use | Department of Public Health and Environment [Internet]. [cited 2018 Sep 4]. Available from: https://www.colorado.gov/pacific/cdphe/pregnancy-risk-assessment-monitoring-system-pramsmonitoring-trends-marijuana-use

34. Metz TD, Silver RM, McMillin GA, Allshouse AA, Jensen TL, Mansfield C, et al. Prenatal Marijuana Use by Self-Report and Umbilical Cord Sampling in a State With Marijuana Legalization. Obstet Gynecol. 2019 1;133(1):98-104. [PubMed: 30531577]

35. Garg M, Garrison L, Leeman L, Hamidovic A, Borrego M, Rayburn WF, et al. Validity of SelfReported Drug Use Information Among Pregnant Women. Matern Child Health J. 2016 1;20(1): 41-7. [PubMed: 26175273]

36. El Marroun H, Tiemeier H, Jaddoe VWV, Hofman A, Verhulst FC, van den Brink W, et al. Agreement between maternal cannabis use during pregnancy according to self-report and urinalysis in a population-based cohort: the Generation R Study. Eur Addict Res. 2011;17(1):3743. [PubMed: 20975275] 


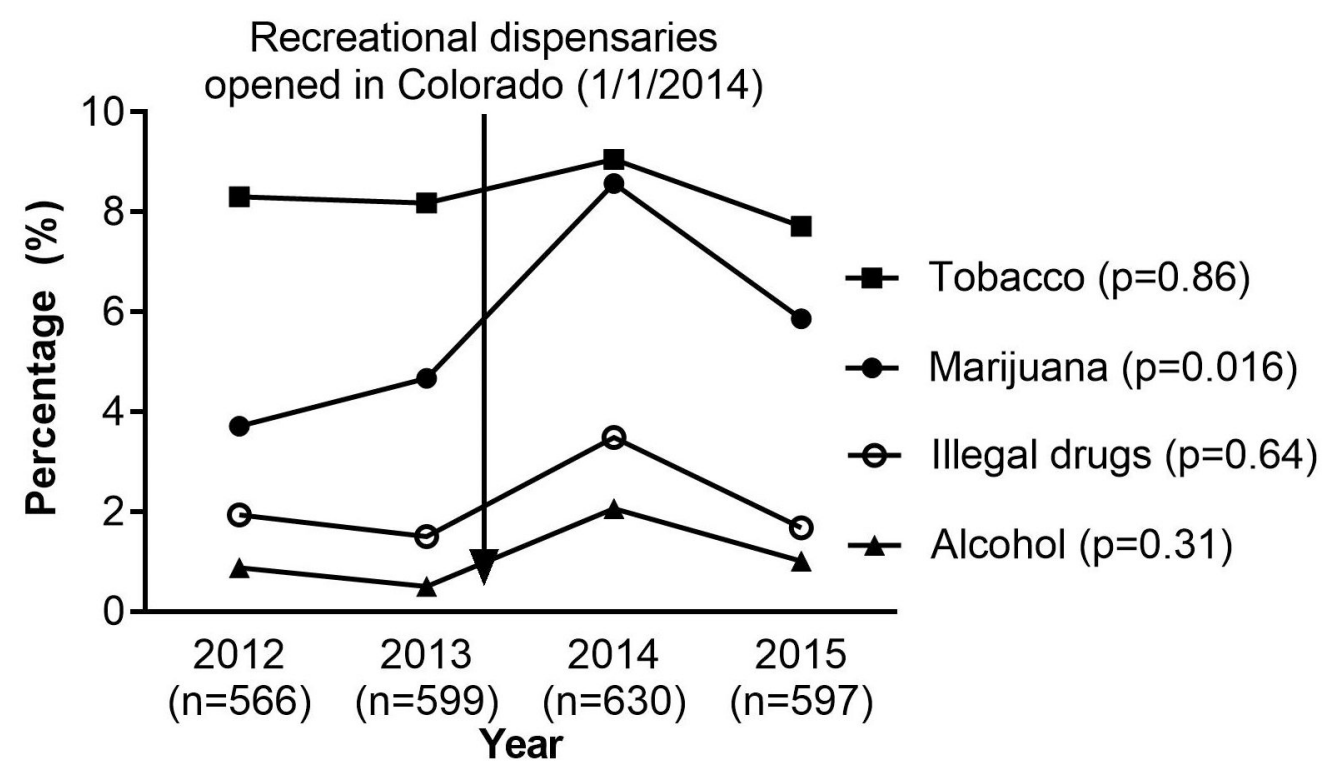

Figure 1. Marijuana and other substance use over time, 2012-15

Substance use by year across marijuana legalization for recreational use in Colorado. Use as measured by self-report or as detected by biological sampling. The arrow indicates the opening of recreational marijuana dispensaries in Colorado on January 1, 2014. 
Table 1.

Demographics of study population before and after legalization

\begin{tabular}{|l|l|c|c|l|}
\hline Characteristic & Value & Before $\mathbf{n = 1 1 6 5}(\boldsymbol{\%})$ & After $\mathbf{n = 1 2 2 7}(\boldsymbol{\%})$ & $\boldsymbol{P}$ \\
\hline Ethnicity & Hispanic & $368(32.5)$ & $319(27.4)$ & 0.008 \\
\hline Race & Black or African American & $188(16.1)$ & $205(16.7)$ & 0.707 \\
\hline & Native American or Alaskan & $5(0.4)$ & $5(0.4)$ & 0.935 \\
\hline & Asian & $37(3.2)$ & $52(4.2)$ & 0.17 \\
\hline & Native Hawaiian or Other Pacific Islander & $7(0.6)$ & $3(0.2)$ & 0.177 \\
\hline & White & $562(48.25)$ & $599(48.8)$ & 0.777 \\
\hline & More than one race & $1(0.1)$ & $2(0.2)$ & 0.594 \\
\hline & Other & $322(27.6)$ & $287(23.4)$ & 0.017 \\
\hline & Patient Refused & $1(0.1)$ & $2(0.2)$ & 0.594 \\
\hline & Unknown & $10(0.9)$ & $9(0.7)$ & 0.731 \\
\hline Maternal age (years) & Geometric mean [95\%CI] & $27.8[27.40,28.14]$ & $28.2[27.83,28.55]$ & 0.109 \\
\hline Marital Status & Married or Living with Partner & $677(59.8)$ & $699(60.1)$ & 0.075 \\
\hline & Single or significant other & $394(34.8)$ & $420(36.1)$ & \\
\hline & Divorced or Legally Separated & $32(2.8)$ & $15(1.3)$ & \\
\hline & Unknown & $30(2.6)$ & $30(2.6)$ & \\
\hline & 1 & $1133(97.3)$ & $1188(96.8)$ & 0.705 \\
\hline & 2 & $31(2.7)$ & $36(2.9)$ & \\
\hline & 3 & $1(0.1)$ & $2(0.2)$ & \\
\hline & 4 & $0(0.0)$ & $1(0.1)$ & \\
\hline
\end{tabular}


Table 2.

Marijuana and other substance use, 2012-2015

\begin{tabular}{|c|c|c|c|c|c|c|}
\hline Substance Use Measure & $\begin{array}{c}2012 \mathrm{n}=566 \\
(\%)\end{array}$ & $\begin{array}{c}2013 \mathrm{n}=599 \\
(\%)\end{array}$ & $\begin{array}{c}2014 \mathrm{n}=630 \\
(\%)\end{array}$ & $\begin{array}{c}2015 \mathrm{n}=597 \\
(\%)\end{array}$ & $P$ & $P$ trend \\
\hline Self-reported marijuana use & $16(2.8)$ & $22(3.7)$ & $45(7.1)$ & $29(4.9)$ & 0.002 & 0.0139 \\
\hline $\begin{array}{l}\text { Meconium sample at delivery positive for } \\
\text { marijuana }\end{array}$ & $6(1.1)$ & $0(0.0)$ & $4(0.6)$ & $8(1.3)$ & 0.043 & 0.3319 \\
\hline $\begin{array}{l}\text { Urine sample at first prenatal visit } \\
\text { positive for marijuana }\end{array}$ & $3(0.5)$ & $9(1.5)$ & $13(2.1)$ & $5(0.8)$ & 0.076 & 0.4828 \\
\hline $\begin{array}{l}\text { Urine sample at delivery positive for } \\
\text { marijuana }\end{array}$ & $2(8.7)$ & $1(5.3)$ & $14(31.8)$ & $2(13.3)$ & 0.045 & 0.0523 \\
\hline $\begin{array}{l}\text { Any marijuana by self-report or } \\
\text { biological sampling }\end{array}$ & $21(3.7)$ & $28(4.7)$ & $54(8.6)$ & $35(5.9)$ & 0.002 & 0.0158 \\
\hline $\begin{array}{l}\text { Meconium or urine sample positive for } \\
\text { opioids }\end{array}$ & $3(0.5)$ & $3(0.5)$ & $7(1.1)$ & $2(0.3)$ & 0.331 & 0.9792 \\
\hline $\begin{array}{l}\text { Meconium or urine sample positive for } \\
\text { illegal drugs }\end{array}$ & $4(0.7)$ & $5(0.8)$ & $8(1.3)$ & $6(1.0)$ & 0.77 & 0.4593 \\
\hline $\begin{array}{l}\text { Any illegal drugs or opioids by self-report } \\
\text { or biological sampling }\end{array}$ & $11(1.9)$ & $9(1.5)$ & $22(3.5)$ & $10(1.7)$ & 0.064 & 0.6432 \\
\hline Self-reported tobacco use & $47(8.3)$ & $49(8.2)$ & $57(9.0)$ & $46(7.7)$ & 0.862 & 0.8587 \\
\hline Self-reported alcohol use & $5(0.9)$ & $3(0.5)$ & $13(2.1)$ & $6(1.0)$ & 0.059 & 0.3098 \\
\hline
\end{tabular}

$P$ values from both overall chi-square and additionally a test of trend. 
Table 3.

Secondary outcomes among singleton deliveries: neonatal, obstetric, and delivery characteristics

\begin{tabular}{|l|c|c|c|}
\hline Characteristic & Before $\mathbf{n = 1 1 3 3}(\boldsymbol{\%})$ & After $\mathbf{n = 1 1 8 8}(\boldsymbol{\%})$ & $\boldsymbol{P}$ value \\
\hline Preterm Birth & $141(12.6)$ & $144(12.2)$ & 0.802 \\
\hline Fetal congenital anomaly & $58(5.4)$ & $48(4.2)$ & 0.191 \\
\hline Fetal growth restriction & $32(2.9)$ & $60(5.1)$ & 0.006 \\
\hline Stillbirth & $15(1.4)$ & $15(1.3)$ & 0.904 \\
\hline Neonatal death & $11(1.5)$ & $15(1.8)$ & 0.567 \\
\hline Maternal death & 0 & 0 & - \\
\hline Preeclampsia & $80(7.1)$ & $78(6.7)$ & 0.686 \\
\hline Gestational diabetes & $74(6.7)$ & $92(7.9)$ & 0.252 \\
\hline Spontaneous preterm labor & $60(5.5)$ & $84(7.3)$ & 0.073 \\
\hline Mode of Delivery & & & 0.87 \\
\hline Spontaneous Vaginal & $785(72.4)$ & $830(73.8)$ & \\
\hline Forceps & $16(1.5)$ & $16(1.4)$ & \\
\hline Vacuum & $13(1.2)$ & $11(1.0)$ & \\
\hline Cesarean & $271(25.0)$ & $268(23.8)$ & \\
\hline Gestational age at delivery, weeks (mean, SE) & $38.7(0.09)$ & $38.6(0.09)$ & 0.465 \\
\hline Z score group & & & 0.926 \\
\hline SGA (<10th percentile) & $165(15.2)$ & $162(14.6)$ & \\
\hline AGA & $859(79.0)$ & $881(79.4)$ & \\
\hline LGA (>90th percentile) & $64(5.9)$ & $67(6.0)$ & \\
\hline Z score (Mean, SE) & $170(15.0)$ & $159(13.4)$ & 0.263 \\
\hline Any time in NICU & $100(8.8)$ & $113(9.5)$ & 0.567 \\
\hline More than 2 days in NICU & & $-27(0.03)$ & 0.893 \\
\hline & & & \\
\hline & & & \\
\hline & & & \\
\hline
\end{tabular}

SGA is small for gestational age. LGA is large for gestational age. NICU is Neonatal Intensive Care Unit.

${ }^{1}$ Neonatal sex was missing for $\mathrm{n}=45$ women before legalization and $\mathrm{n}=78$ women after legalization, which did not allow for calculation of a $\mathrm{Z}$ score in this subset. 